Michele L. Hartigan BSN SRNA

Jeanette L. Cleary RN CRNA, Jeffrey B. Gross MD, David W. Schaffer MD

\title{
A comparison of pre- treatment regimens for minimizing the haemodynamic response to blind nasotracheal intubation
}

The authors determined the cardiovascular effects of blind nasuracheal inubation in four randomized groups. of 25 patient each After induction of andesthesia with $J$ thiopentone $4 \mathrm{ng} \cdot \mathrm{kg}^{-1}$, patients in group A received no pretreatment, while patients in group $B$ received $I V$ lidocaine $1.5 \mathrm{mg} \cdot \mathrm{kg}^{-1}$. Three minutes before induction, patients in group $C$ received 0.25 per cent phenlephrine nasal spray $10.2 \mathrm{mg}$ in each nostril); those in group $D$ received ten per cent lidocaine nasal spray (30 $\mathrm{mg}$ in each nostril). After intubation, mean arterial pressures (MAP) were highest in group $B$ (IV lidocaine) patients ( $)<$ $0.05)$, remaining significantly elevated for $5 \mathrm{~min}$. Conversely, within four minutes after intubation, MAP of group $D$ (ten per cent nasal lidocaine spray) patient. were below control $(p<0.05)$, and lower than those of any oher group $(p<0.05)$. MAP of group $A$ and $C$

\section{Key words}

ANAESTHETICS, LOCAL: lidocaine; INTUBATION: nasotracheal; SYMPATHETIC NERVOUS SYSTEM: sympathomimetic agents, phenylephrine.

From the Departments of Ancsthesia, Nazareth Hospital, University of Pennsylvania, and Philadelphia Veterans Administration Mcdical Center, Philadelphia, PA

Address correspondence to: Dr. Jeflrey B. Gross, Department of Anesthesia (112), Philadelphia Veterans Administration Medical Center, University and Wood land Avenues, Philadelphia, PA 19104, USA

Presented in part at the annual meeting of the Americun Society of Anesthesiologists, Atlanta, Georgia, October, 1983. patients increased after inubation, but not as much as in group $B$ patients $(p<0.05)$. There were no adverse effects from the lidocuine nasal spray. Ten per cent lidocaine nasal spray is a safe and effective way to minimize the MAP increases which topically arcompan: blind nasurachest intubation in lightly ancesthemad patients.

Laryngoscopy ${ }^{\prime}$ and endotracheal intubation ${ }^{2}$ cause significant increases in patients' heart rates and blood pressures which may lead to myocarcial ischaemia and arrhythmias ${ }^{3}$ as well as cerebrovascular accidents. ${ }^{4}$ Denlinger et al. demonstrated that topical analgesia of the trachea using four per cent lidocaine spray can significantly decrease (although not completely eliminate) the hypertensive response to orotracheal intubation. ${ }^{5}$ Hamill and coworkers ${ }^{6}$ and Abou-Madi et al. ${ }^{7}$ demonstrated a similar attenuation of the pressor response to orotracheal intubation after intravenous lidocaine $\left(1.5 \mathrm{mg} \cdot \mathrm{kg}^{-1}\right)$.

The only available information regarding blind nasotracheal intubation is that of Prys-Roberts $t$ al., who found that when this procedure was facilitated by ten per cent $\mathrm{CO}_{2}$ inhalation, there was no significant increase in heart rate or mean arterial blood pressure in four patients, two of whom had previously demonstrated significant hypertensive responses to direct laryngoscopy. ${ }^{3}$ There was no topical anaesthesia provided to either the nasal or tracheal mucosa prior to intubation of these patients.

We have been performing increasing numbers of 
blind nasotracheal intubation for oral surgery on outpatients, and have frequently observed unacceptable increases in both heart rate and blood pressure after intubation is accomplished. This study was designed to determine if these responses could be ablated by lidocaine, either injected intravenously or applied topically to the nasal mucosa as a spray or an ointment.

\section{Methods}

We studied 147 consenting outpatients, ASA physical status $I$, undergoing dental extractions under general anaesthesia. Patients ranged in age from 15 to 41 years, and had no contraindication to nasotracheal intubation. Patients fasted for at least eight hours before induction of anasthesia, and received no premedication be fore entry into the study, which had the approval of our institutional review committee.

Random assignment of 25 successfully intubated patients to each of four pretreatment groups (Table) was achieved as follows: 100 index cards were placed in a box; 25 cards were labeled for each group. Before each patient entered the operating room, a card was selected at random and the patien was assigned to the indicated group. If blind nasal intubation was successfully accomplished within 30 sec, the patient was included in the study, and the card was destroyed. If laryngoscopy was required, the patient was not studied further, and his card was returned to the box.

After starting an intravenous infusion of five per cent dextrose in water and establishing electrocardiographic and blood pressure (Dinamapp (R)) monitoring, we recorded baseline heart rate (HR) and mean arterial blood pressure (MAP) data. The microprocessor-controlled Dinamapp (R) first inflates the cuff to a pressure above the patient's previous systolic reading. The cuff is then deflated in increments of approximately $1 \mathrm{kPa}(8 \mathrm{mmHg})$; after each deflation, the magnitude of cuff pressure oscillations is automatically measured. Mean arterial pressure, which has been shown to correspond to the lowest cuff pressure associated with maximum pressure oscillations, ${ }^{8}$ is displayed automatically following each determination.

All patients then received d-tubocurarine $(3 \mathrm{mg})$, fentanyl $(100 \mu \mathrm{g})$, and atropine $(0.4 \mathrm{mg})$ intravenously. In addition, patients in group $C$ reccived a transnasal spray of 0.25 per cent phenylephrine $(0.2$
Ing in each nostril) while those in group $D$ received a ten per cent lidocaine spray transnasally ( $30 \mathrm{mg}$ in each nostril). Three minutes later, we again recorded mean arterial pressure and heart rate and began preoxygenation. Thirty seconds later, each patient received IV thiopentone $4 \mathrm{mg} \cdot \mathrm{kg}^{-1}$; immediately thereafter, patients in group $B$ and $A$ reccived intravenous injections of lidocaine $1.5 \mathrm{mg} \cdot \mathrm{kg}^{-1}$ or an equivalent volume of normal saline respectively.

When the eyelash reflex disappeared, we administered succinylcholine $1.25 \mathrm{mg} \cdot \mathrm{kg}^{-1}$ IV, and waited $60 \mathrm{sec}$ for it to take effect. We then passed a 6.5 or $7.0 \mathrm{~mm}$ (i.d.) cuffed, disposable endotracheal tube through the nose into the oropharynx. Endotracheal tubes were lubricated with $K-Y(R)$ jelly for all patients except those in group $C$, whose tubes were lubricated with five per cent lidocaine ointment. We gently advanced the endotracheal tubes through the oropharynx toward the trachea; even in the absence of spontaneous ventilation, the trachea was often successfully intubated on the first pass. If resistance was encountered, palpation of the neck frequently revealed that the tube had entered a pyriform sinus; the tube was then turned to direct it toward the midline and into the trachea. This previously described technique, ${ }^{9}$ which we use routinely in oral surgery patients, enables us to intubate more than two-thirds of these patients in less than $30 \mathrm{sec}$. An additional advantage of this technique is that patients are fully relaxed, making it easy for us to intubate the trachea under direct vision should we be unable to accomplish blind nasotracheal intubation.

Tube placement was verified by applying gentle positive pressure through the tube and observing chest movement and breath sounds. Forty-seven patients who could not be intubated blindly within $30 \mathrm{sec}$ were intubated under direct vision. No further data were recorded for these patients, who were evenly distributed among the groups and were replaced as described above.

Following intubation, $\mathrm{N}_{2} \mathrm{O} 70$ per cent in $\mathrm{O}_{2} 30$ per cent maintained anaesthesia. Ventilation was controlled manually, and HR and MAP were recorded at one-minute intervals. Five minutes after intubation, the study was terminated, and surgical anaesthesia was established and maintained with a potent inhalational agent.

Two-way analysis of variance and Tukey's test for multiple comparisons served to compare MAP 
TABLE Summary of treatment regimens

\begin{tabular}{|c|c|c|c|c|}
\hline & Group $A$ & Grotp $B$ & Group $C^{+}$ & Grom $D$ \\
\hline Nusal & None & Nọne & $0.25 \%$ & $10 \%$ \\
\hline Topicalization & & & Phenylephrine & lidocains \\
\hline Lubricant & Bland & Bland* & $5 \%$ Lidocaine ointment & Bland* \\
\hline $\begin{array}{l}\text { Intravenous Supplement } \\
\text { (immediately altęr thiopentone) }\end{array}$ & Saline & Lidocaine ( $1.5 \mathrm{mg} \cdot \mathrm{kg}^{-1}$ ) & None & None \\
\hline
\end{tabular}

*K-Y Jelly (Johnson and Johnson).

tGroup $C$ corresponds to our standard intubation technique.

and HR data between groups. Within each group, we compared $H R$ and MAP values at one-minute intervals after intubation with the values observed just before induction, using Dunnett's test for multiple comparisons with a control. ${ }^{10}$ Values of $p$ $<0.05$ were taken as indicating statistical significance.

\section{Results}

Treatment regimens are summarized in the Table. Meen patient ages (range 20.6-22.5 yr) and weights (range $624-64.5 \mathrm{~kg}$ ) were similar among the four groups. There were no significant differences in mean arterial blood pressures (MAP) or heart rates (HR) among the various groups on arrival in the operating room (Figures 1, 2), Following the intravenous d-tubocurarine, atro-

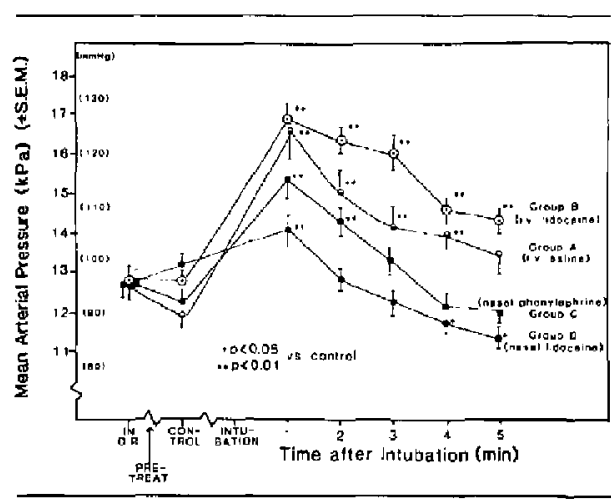

FIGURE 1 Mean artcrial pressure data for four groups of patients (see rext) undergoing blind nasotracheal intubation. Pressures were measured when patients entered the operating room (ir. O.R.), after atropine ( $.4 \mathrm{mg}$ IV and fentanyl $100 \mu \mathrm{g}$ IV (control), and at one-tninute intervals after intubation was accomplished. P values compare post-intubation values with corresponding control values measured after atropine and fentanyl pretreatment. There were 25 patients in each group.

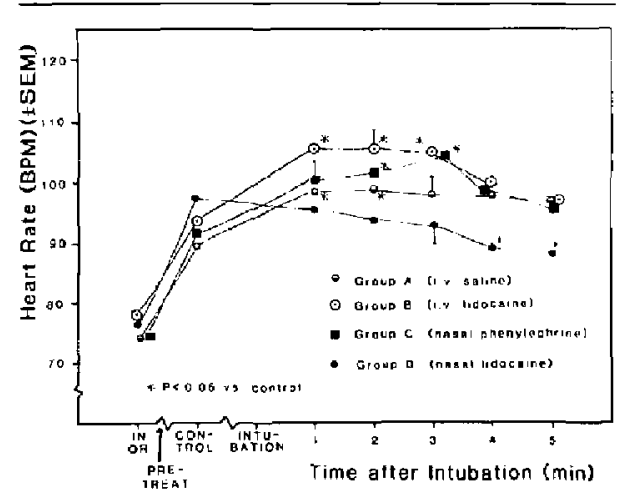

FIGURE 2 Heart rate data for four groups of patients isee (ext) undergoing blind nasotracheal intubation. Heart rates were measured when patients entered the operating toom (in O.R.). after atropine $0.4 \mathrm{mg} \mathrm{IV}$ and fentanyl $100 \mu \mathrm{g}$ IV (control), and at one-minute intervals after intubation was accomplished. As expected, atropine pretreatment increased heart ratc in all four groups. To rcflect changes in heart rate associaled with intubation. P values compare post-intubation measurements with corresponding measurements made offer atropine administation (control). Note that four and five minutes after intubarion, heart rates of group D patients were significantly lower than control.

pine, and fentanyl, there was a significant increase in the HR of patients in all four groups $(p<0.01$ ) which we attributed to the vagolytic effect of the atropine; however, there remained no significant differences between the groups. In all groups, MAP was unchanged by fentanyl and atropine administration.

Mean arterial pressures of patients receiving IV lidocainc (group B) increased from $12.6 \pm 0.3 \mathrm{kPa}$ $(94.7 \pm 2.0 \mathrm{mmHg}, \overline{\mathrm{x}} \pm \mathrm{SEM})$ to $16.8 \pm 0.4 \mathrm{kPa}$ $(126.0 \pm 2.8 \mathrm{mmHg})$ after blind nasotracheal intubation $(p<0.01)$; MAP in these patients remained significantly elevated throughout the fiveminute observation period, and were higher than 
thosc of any other group (Figure 1, p < 0.05). In patients receiving ten per cent nasal lidocaine spray (group D), MAP increases after intubation were much less pronounced. From a control value of 13.1 $\pm 0.3 \mathrm{kPa}(98.7 \pm 1.9 \mathrm{mmHg})$, MAP of these patients increased to only $14.0 \pm 0.4 \mathrm{kPa}$ (105.2 \pm $3.0 \mathrm{mmHg}$ ) one minute after intubation; five minutes after intubation, MAP had decreased to $11.4 \pm$ $0.2 \mathrm{kPa}(85.5 \div 1.8 \mathrm{mmHg})$, significantly lower than control ( $p<0.05$ ). In fact, MAP of group D patients were significantly lower than those of patients in any other group throughout the fiveminute observation period (Figure $1, \mathrm{p}<0.05$ ).

While the atropine pretrcatment caused significant increases in heart rate of patients in all groups, it is apparent from Figure 2 that endotracheal intubation caused further significant increases in the HR of patients in groups $\mathrm{A}, \mathrm{B}$, and $\mathrm{C}$, while patients in group D exhibited significant decreases in their HR 4 and 5 min after intubation. When the overall $\mathrm{HR}$ data were evaluated by analysis of variance and Tukey's test, we found that patients in groups B and $C$ had significantly higher post-intubation HR than patients in group $\mathrm{D}(\mathrm{p}<0.05)$. Differences between groups $A$ and $D$ were not significant.

We did not formally collect epistaxis data as part of this study. However, it was our clinical impression that there was less post-extubation bleeding among patients who received phenylephrine nasal spray (group C).

\section{Discussion}

Because the manufacturer of the ten per cent lidocaine metered spray was unable to provide us with a suitable placebo, our study was of necessity not double blind. However, patient sclection was randomized, and MAP and HR measurements were automated to minimize observer bias. We were able to show that in the absence of therapeutic intervention, blind nasotracheal intubation causes significant increases in both HR and MAP of patients anaesthetized with thiopentone $4 \mathrm{mg} \cdot \mathrm{kg}^{-1}$ (group A). Patients receiving IV lidocaine (group B) demonstrated signilicantly higher MAP than controls (group A). This may be related to the centrally mediated increase in heart rate and stroke volume which has been shown to result from $1-2 \mathrm{mg} \cdot \mathrm{kg}^{-1}$ IV lidocaine. ${ }^{11}$

If the lidocaine spray were exerting its bencficial effect through systemic absorption, we would have expected IV lidocaine to be even more effective; clearly this was not the case. Therefore, the superiority of ten per cent nasal lidocaine spray in ablating the cardiovascular response to nasotracheal intubation suggests that the most noxious aspect of this procedure is the passage of the tube through the nose and pharyn $x$ - the areas best anaesthetized by the lidocaine spray.

Other methods for avoiding the hypertension accompanying intubation include deep inhalational anaesthesia and moderate doses of fentanyl. ${ }^{12}$ However, because emergence may be delayed, these techniques may not be as well suited to outpatient anaesthesia as is light general anaesthesia with appropriate topicalization.

Hamill et al. reported that IV lidocaine 1.5 $\mathrm{mg} \cdot \mathrm{kg}^{-1}$ is more effective than laryngotracheally administered lidocaine ( $4 \mathrm{ml}$ of four per cent solution) for ablating the haemodynamic response to endotracheal intubation. ${ }^{6}$ Their results require interpretation, however, because the investigators made no attempt to provide topical anaesthesia to the tongue and pharynx before laryngoscopy and tracheal spraying were performed. Furthermore, patients receiving laryngotracheal lidocaine spray underwent laryngoscopy twice, while those in the IV lidocaine group were laryngoscoped only once. Because of these inconsistencies in study design, it is not surprising that laryngotracheal lidocainc proved to be less effective than IV lidocaine. In contrast, our blind nasotracheal technique avoided the stimulation associated with laryngoscopy; the only stimulation after induction of anaesthesia was that related to the actual passage of the tracheal tube. Therefore, it is not surprising that our results differ from those of Hamill et al.

One must, of course, be concerned with tho possible adverse effects of any therapeutic intervention. The ten per cent lidocaine spray is supplied with a metered-dose valve, which delivers $10 \mathrm{mg}$ per spray. Each patient received a total of six sprays, resulting in a total administered dose of 60 mg. Since our lightest patient weighed $50 \mathrm{~kg}$, patients received no more than $1.2 \mathrm{mg} \cdot \mathrm{kg}^{-1}$ of lidocaine by the nasal route. Even if uptake of lidocaine from the nasal mucosa were immediate and complete, peak blood levels could not exceed those obtained by intravenous injection of a similar dose.$^{13}$ In the intensive care setting, larger doses of lidocaine (typically $1.5 \mathrm{mg} \cdot \mathrm{kg}^{-1}$ ) are routinely 
given without CNS toxicity; therelore, there is essentially no risk of toxicity from transnasal absorption of the lidocaine doses we employed.

Some of our patients complained of a burning sensation in the nose which lasted less than $30 \mathrm{sec}$ after application of the lidocaine spray; this may have contributed to the slight increase in mean arterial pressure which we observed in this group following topicalization (Figure 1).

Because of its superiority in blunting adverse haemodynamic responses, we suggest that ten per cent lidocaine nasal spray be included in the anaesthetic management of paticnts undergoing blind nasotracheal intubation. Of course, the add;tion of vasoconstrictors could be considered to ease the passage of the nasotracheal tube and, perhaps, reduce the indicence of perioperative epistaxis

\section{Acknowledgments}

The authors wish to thank the staffs of the operating and recovery rooms as well as Dr. $\Lambda$ nthony Checchio and members of the Oral Surgery department of Nazareth Hospital for their help in completing this study; we also thank Harry Wollman, MD, Theodore C. Smith, MD, and Bryan Marshalt, MD for their help in reviewing the manuscript.

\section{References}

1 King $B D$, Harris $L C$, Greifenstein FE, Elder JD, Dripps $R D$. Reflex circulatory responses to direct laryngoscopy and tracheal intubation perlorrned during general anesthesia. Anesthesiology 1951; 12: 556-66.

2 King BD, Elder JD, Proctor DF. Dripps RD. Reflex circulatory responses to tracheal intubation performed under topical anesthesia. Anestleesiology 1954: 15: 231-3.

3 Irys-Roberts $C$, Greene LT, Meloche R, Foex $P$. Studies of anaesthesia in relation to hypertension $\mathrm{II}$ : haemodynamic consequences of induction and endotracheal intubation. Br J Anaesth 1971; 43: 53I-46.

4 Fox EJ, Sklar GS, Hill CH, Villanueva $R$, King $B D$. Complications related to the pressor response to endotracheal intubation. Anesthesiology 1977; 47 524-5.

5 Deniinger $J K$, Ellison $N$, Ominsky AJ. Effects of intratracheal lidocaine on circulatory responses to tracheal intubation. Anesthesiology 1974; 41: 409-12.
6 Hamill JF, Bedford RF, Weaver DC, Colohan AR. Lidocaine before endotracheal intubation: intravenous or laryngotracheal? Anesthesiology 1981: 55: 578-81.

7 Abou-Madi MN, Keszler H, Yacoub JM. Cardiovascular reactions to laryngoscopy and tracheal intubation following small and large intravenous doses of lidocaine. Can Anaesth Soc J 1977; 24: 12-19.

8 Yelderman $M$, Ream $A K$. Indirecl measurement of mean blood pressure in the anesthetized patient. Anesthesiology 1979; 50: 253-5.

9 Atkinson RS, Rushman GB, Lee JA. A synopsis of anaesthesia. 9th ed. London: John Wright and Sons, Ltd., 1982; 228.

10 Walpole RE, Myers RH. Probability and statistics for engineers and scientists. 2nd ed. New York: Macmillan, 1977; 383-5.

11 dejong $R H$. Physiology and pharmacology of local anesthesia. Springfield: Charles $C$. Thomas, 1970: 146.

12 Martin DE, Rosenberg H, Aukburg SJ, et al. Lowdose fentanyl blunts circulatory responses to tracheal intubation. Anesth Aralg 1982;61:680-4.

13 Fingl $E$, Woodbury DM. General principles. In: Goodman LS, Gilman A, eds. The pharrnaculogical basis of therapeutics. Sth ed. New York: Macnillan, 1975; 5-8 


\section{Résumé}

Ce travail a porté sur l'observation des effets cardiovasculaires de l'intubation naso-trachéale à l'aveugle chez 100 malades distribuér au hasard également dams quatre groupes différents. Après l'induction de l'anesthésie au thiopental intraveineur (4 $\left.\mathrm{mg} \cdot \mathrm{kg}^{-1}\right)$, tes patients du groupe A ne reģurem aucunc médication, ceux du groupe $B$ regurent de la lidocaïne intraveineuse à $1.5 \mathrm{mg} \cdot \mathrm{kg}^{-1}$. Trots minutes avant l'induction les patients du groupe $C$ reçureni de la phényléphrine 0.25 pour cent en vaporisarion nasale (0.2 $\mathrm{mg}$ dans chaque narine). Les malades du groupe $D$ reçurent de la lidocaïne dix pour cent en vaporisation nasale $(30 \mathrm{mg}$ dans chaque narine). Après I'intubation les pressions artérielles moyennes (MAP) étaiem plus élevées chez les patients du groupe $B$ (lidocaine $I V)(p<0.05$ ). Les pressions se sont maintenue. élevées pendant cinq minutes.

Inversement, moins de quatre minutes après l'intubarion, les pressions arrérielles des patients du groupe $D$ (lidocaïne dix pour cent par voie nasale) étaient en bas des valeurs de conrôle ( $p<0.05$ ) et plus basses que tes pressions trouvées dans les autres groupes ( $p<0.05$ ). Les pressions artérielles moyennes des patients des groupes $A$ et $C$ ont augmenté après I"intubation mais moins que chez les patients du groupe $B(p<0.05)$. On $n ' a$ observé aucun effet indésirable de la vaporisation nasale de licocaine. La lidocaine à dix pour cent en vaporisation nasale représente donc un moyen sûr et efficace de diminuer la réponse hypertensive qui accom pagne régulierement l' intubation naso-trachéle chez les patients sous anesthésie légère. 